\title{
Pengaruh Media Permainan \\ Monopoli terhadap Hasil Belajar Siswa dalam Pembelajaran IPS Gugus 15 Kota Bengkulu
}

\author{
Yela Purnama Sari \\ Universitas Bengkulu \\ yelapurnamasri@gmail.com \\ Herman Lusa \\ Universitas Bengkulu \\ hermandatuk105@gmail.com
}

Ansyori gunawan

Universitas Bengkulu

agunawan@unib

\begin{abstract}
This study aimed to find the effect of using monopoli game media towards learning result on social science major at fourth grade of SDN Gugus 15 Kota Bengkulu. This research is quantitative, using experiment method, with The Matching Only Pretest-Posttest Control Group Design. The instrument used was test sheet in multiple choice form. The test was taken two times, before and after giving treatening to the sample class. The sample in this research was the students in IVB of SDN 76 Kota Bengkulu (control group) and the students in IV of SDN 104 Kota Bengkulu (experimental group). The $t$ value gotten was $(3,668)>$ ttable $(1,668)$. The result of $t$ value was higher than $t$ table, so it can be concluded that there are significant effect of using monopoli game media towards learning result on social science major at fourth grade SDN Gugus 15 Kota Bengkulu.
\end{abstract}

Keywords: Monopoli Media, Social Science Learning Result

\begin{abstract}
Abstrak
Penelitian ini bertujuan untuk mengetahui pengaruh penggunaan media game monopoli terhadap hasil belajar jurusan IPS di kelas empat SDN Gugus 15 Kota Bengkulu. Penelitian ini adalah kuantitatif, menggunakan metode eksperimen, dengan The Matching Only PretestPosttest Control Group Design. Instrumen yang digunakan adalah lembar tes dalam bentuk pilihan ganda. Tes diambil dua kali, sebelum dan sesudah memberikan perlakuan pada kelas sampel. Sampel dalam penelitian ini adalah siswa kelas IVB SDN 76 Kota Bengkulu (kelompok kontrol) dan siswa kelas IV SDN 104 Kota Bengkulu (kelompok eksperimen). Nilai t yang didapat adalah $(3,668)>$ ttabel $(1,668)$. Hasil nilai t lebih tinggi dari t tabel, sehingga dapat disimpulkan bahwa ada
\end{abstract}


pengaruh yang signifikan penggunaan media game monopoli terhadap hasil belajar jurusan IPS di kelas IV SDN Gugus 15 Kota Bengkulu.

Kata kunci: Media Monopoli, Hasil Belajar IPS

\section{Pendahuluan}

Berdasarkan hasil pengamatan peneliti selama melaksanakan magang III selama 3 bulan dari akhir bulan Agustus sampai awal bulan November 2017, ditemukan masalah bahwa siswa sulit memahami materi pelajaran IPS. Hal ini disebabkan karena (1) guru masih menggunakan metode ceramah, (2) masih dominannya peran guru dalam pembelajaran, (3) kurangnya pemanfaatan media pembelajaran sesuai dengan materi IPS, membuat siswa kurang tertarik dalam mengikuti proses pembelajaran, (4) guru belum mengorganisasikan siswa ke dalam kelompok. Hal ini bisa membuat siswa menjadi jenuh dan bosan, sehingga materi pembelajaran tidak terserap dengan baik. Dalam proses belajar guru tidak hanya mendidik, tetapi guru berusaha untuk memberikan pembelajaran kepada siswa agar dapat tercapai target pembelajaran berdasarkan tujuan pembelajaran IPS.

Suatu proses pembelajaran dinyatakan berhasil apabila tujuan pembelajaran tercapai dengan baik. Untuk mencapai tujuan pembelajaran IPS yang optimal, hendaknya seorang guru menggunakan media yang dapat melibatkan siswa dapat aktif dalam proses pembelajaran. Salah satu media yang dapat melibatkan siswa adalah media permainan, karena mediapermainan dapat merangsang daya pikir siswa, emosi siswa, sosial dan fisik siswa. Hal ini sejalan dengan pendapat Desmita (2014: 35) anak usia sekolah dasar (6-12 tahun) memiliki karakteristik yaitu senang bermain, senang bergerak, senang berkerja dalam kelompok, dan senang merasa atau melakukan/memperagakan sesuatu secara langsung. Jadi, cara belajar yang baik adalah belajar dengan benda konkret yaitu dengan melihat, merasakan dan melakukan dengan tangan sendiri.

Monopoli adalah salah satu permainan papan yang terkenal di dunia.Menurut Husna (2009: 152) tujuan permainan ini adalah untuk menguasai semua petak di atas papan melalui pembelian, penyewaan dan pertukaran properti yang di sederhanakan. Aturan dalam permainan ini yaitu setiap pemain melemparkan dadu secara bergiliran untuk memindahkan dadu secara bergiliran untuk memindahkan bidaknya, dan apabila pemain mendarat di petak yang belum dimiliki oleh pemain lain, pemain tersebut dapat membeli petak tersebut sesuai harga yang tertera, apabila petak itu sudah dibeli pemain lain pemain tersebut harus membayar uang sewa yang juga sudah ditetapkan.Media permainan monopoli dipilih karena termasuk salah satu permainan yang relatif digemari anak dan mudah dalam memainkannya. Selain itu media permainan monopoli dipilih karena dengan media permainan ini dapat mengkonkretkan konsep siswa yang abstrak, melatih daya ingat siswa untuk pemahaman konsep dan penugasan, mendorong keberanian siswa untuk mengungkapkan pendapatnya, berimajinasi, serta berpikir secara bebas tanpa takut salah.

Apabila media permainan monopoli diterapkan, diharapkan mampu mengaktifkan siswa selama proses pembelajaran serta dapat memudahkan siswa dalam memperoleh pengetahuan dan keterampilan baru. Selain pengetahuan dan keterampilan yang dapat dikembangkan, siswa juga diajarkan untuk dapat memecahkan masalah yang diberikan oleh guru secara berkelompok, bekerja sama, bertanggung jawab, saling menghargai pendapat dan menerima kritik ataupun saran dari orang lain, serta berani mengemukakan pendapat. Melalui media permainan monopoli siswa akan terlibat secara langsung dan aktif dalam pembelajaran, sehingga akan berpengaruh terhadap hasil belajar siswa. 
Hasil penelitian yang pernah dilakukan oleh Nur Aziza dengan judul "penerapan media monopoli untuk meningkatkan hasil belajar siswa pada mata pelajaran IPA di Sekolah Dasar".Hal ini di buktikan dengan Hasil belajar siswa kelas IV SDN Lemahputro I Sidoarjo setelah mengikuti pembelajaran Ilmu Pengetahuan Alam dengan menerapkan media monopoli selama 2 siklus mengalami peningkatan.Hasil belajar kognitif mengalami peningkatan sebesar $22 \%$.

Berdasarkan uraian di atas, maka penulis tertarik untuk melakukan penelitian dengan judul "Pengaruh Penggunaan Media Permainan Monopoli Terhadap Hasil Belajar Siswa Pada Mata Pelajaran IPS di kelas IV SDN Gugus 15 Kota Bengkulu".

\section{Metode}

Jenis penelitian yang digunakan dalam penelitian ini adalah penelitian kuantitatif, dengan metode eksperimen semu.Dalam metode eksperimen terdapat dua kelompok, yaitu kelompok eksperimen dan kelompok kontrol.

Pada kelompok eksperimen diberikan perlakuan sedangkan kelompok kontrol tidak diberikan perlakuan.Dalam proses pembelajarannya kelompok eksperimen menggunakan media permainan monopolidan kelompok kontrol menggunakan pembelajaran konvensional dengan menggunakan media gambar. Desain penelitian yang digunakan yaitu The Matching only Pretest-Posttest Control Group Design.Untuk memperoleh kelompok yang benar-benar ekuivalen (setara),kelompok eksperimendan control disetaraka melalui pretest untuk melihat kemampuan awal siswa. Setelah diperoleh hasil yang homogen, selanjutnya dilakukan proses pembelajaran pada kedua kelas dengan materi yang sama yaitu mengenal aktivitas ekonomi yang berkaitan dengan sumber daya alam dan potensi lain di daerahnya.

Populasi dalam penelitian ini adalah seluruh siswa kelas IV SDN Gugus 15 Kota Bengkulu.Teknik pengambilan sampel yang digunakan yaitu teknik Cluster Random Sampling.Untuk mendapatkan sampel, peneliti mengacak setiap kelas IV yang ada dalam populasi tersebut untuk diambil menjadi sampel kelompok eksperimen dan kolompok kontrol, kemudian untuk mendapatkan kelompok sampel yang homogen, kelompok yang terpilih kemudian diuji dengan cara melakukan uji homogenitas.Dari proses tersebut kemudian didapat dua kelas untuk dijadikan sampel yaitu kelas IV SDN 76 Kota Bengkulu sebagai kelas control dan kelas IV SDN 104 Kota Bengkulu sebagai kelas eksperimen.

Instrumen penelitian dikenal juga dengan istilah alat ukur.Menurut Sugiyono (2017: 102) instrumen penelitian adalah suatu alat yang digunakan mengukur fenomena alam maupun sosial yang diamati. Dalam penelitian ini instrumen yang digunakan adalah lembar tes berupa soal pilihan ganda. Dalam penelitian ini tes soal pilihan ganda yang diberikan oleh peneliti adalah tes hasil belajar kognitif berdasarkan Mengenal aktivitas ekonomi yang berkaitan dengan sumber daya alam dan potensi lain di daerahnya diberikan oleh peneliti. Instrumen yang telah dibuat kemudian divalidasi oleh ahli bidang IPS sebagai validator untuk mengesahkan bahwa instrumen yang dibuat sudah layak untuk digunakan dalam pelaksanaan penelitian.

Teknik pengumpulan data dalam penelitian ini adalah dengan menggunakan tes dalam bentuk tes awal (pre-test) dan tes akhir (post-test).Pretest dilaksanakan satu hari sebelum perlakuan diberikan. Masing-masing siswa diberikan lembar soal pretest. Setelah pretest dilaksanakan, kedua kelompok sampel dilakukan pembelajaran, dimana pada kelompok eksperimen diberi perlakuan dengan menggunakan media permainan monopolidan kelompok kontrol tanpa menggunakan media permainan monopoli, dalam proses pembelajarannya menggunakan 
pembelajaran konvensional. Setelah kegiatan pembelajaran usai, siswa diberikan soal posttest untuk mengetahui kemampuan yang diperoleh siswa setelah mengikuti proses pembelajaran.

Analisis data yang dilakukan meliputi analisis deskriptif yaitu penyajian data melalui tabel, perhitungan skor rata-rata (mean), simpangan baku danvarian; analisis uji prasyarat yaitu dengan melakukan uji normallitas dan uji homogenitas, dan analisis inferensial yaitu dengan uji-tindependen.

\section{Hasil}

Data hasil pretest menunjukkan pada kelompok eksperimen nilai tertinggi yaitu 80 , nilai terendah yaitu 36 dengan dan rata-rata 55,97. Standar deviasi 13,59 dengan varian 186,688 . Pada kelompokkontrol nilai tertinggi yaitu 88 , nilai terendah yaitu 32 dengan rata-rata 55,25. Standar deviasi 16,14, dengan varian 260,500.

Data hasil posttest menunjukkan pada kelompok eksperimen nilai tertinggi yaitu 92, nilai terendah yaitu 36 dengan rata-rata 70,44. Pada kelompokkontrol nilai tertinggi yaitu 88 , nilai terendah yaitu 32 dengan jumlah rata-rata 56,41

Berdasarkan rata-rata pretest pada kelompok eksperimen dan kelompok kontrol, tidak terdapat perbedaan yang signifikan, artinya kemampuan awal yang dimiliki siswa pada kelompok eksperimen dan kelompok kontrol adalah sama. Sedangkan pada hasil posttest, terdapat perbedaan yang signifikan rata-rata pada kelompok eksperimen dankelompok kontrol.

Sebelum melakukan pengujian hipotesis menggunakan uji-t, peneliti melakukan uji prasyarat hipotesis yaitu uji normalitas dan uji homogenitas.Hal ini bertujuan agar data yang ingin diuji berdistribusi normal dengan varian yang homogen.Uji normalitas dan uji homogenitas yang peneliti lakukan yaitu data hasil pretest dan posttest siswa.

Berdasarkan uji normalitas hasil pretest dan posttest siswa, diperoleh hasil pretest maupun posttest pada kelompok eksperimen dan kelompok kontrol berdistribusi normal.Padahasilpretest kelompokeksperimendiperoleh $x^{2}$ hitung=-42,06dengan $x^{2}$ tabel=11,070danpadakelompokkontrol $x^{2}$ hitung $=-61,66$, dengan $x^{2}$ tabel $=11,070$. Padahasilposttestkelompokeksperimendiperoleh $x^{2}$ hitung $=-72$,30dengan $x^{2}$ tabel= 11,070danpadakelompokkontrol $x^{2}$ hitung $=-28,52$ dengan $x^{2}$ tabel $=11,070$.

Berdasarkan uji homogenitas hasil pretest siswa, diperoleh $\mathrm{F}_{\text {hitung }}=1,41$ dengan $\mathrm{F}_{\text {tabel }}$ $=1,80$. Dari hasil perhitungan menunjukkan $\mathrm{F}_{\text {hitung }}<\mathrm{F}_{\text {tabel, }}$ maka dapat disimpulkan bahwa hasil pretest siswa pada kelompok eksperimen dan kelompok kontrol adalah homogen.Berdasarkan uji homogenitas hasil posttest siswa, Diperoleh $\mathrm{F}_{\text {hitung }}=1,5$ denganF $F_{\text {tabel }}=1,80$. Dari hasil perhitungan menunjukkan $\mathrm{F}_{\text {hitung }}<\mathrm{F}_{\text {tabel, }}$, maka dapat disimpulkan bahwa hasil posttest siswa pada kelompok eksperimen dan kelompok kontrol adalah homogen. Setelah uji prasyarat hipotesis selesai dilakukan dengan hasil data yang normal dan homogen, maka peneliti melakukan uji hipotesis yaitu dengan uji-t.

Berdasarkan hasil uji hipotesis (Uji-t) pretest siswa pada kelompokeksperimen dan kelompok kontrol diperoleh thitung $=0,21$, dengan $t_{\text {tabel }}=1,678$. Karena $t_{\text {hitung }}<t_{\text {tabel }}$,maka tidak terdapat perbedaan hasil pretest antara kelompok eksperimen dan kelompok kontrol. Berdasarkan hasil uji hipotesis (Uji-t) posttest siswa pada kelompokeksperimen dan kelompok kontrol diperoleh $t_{\text {hitung }}=3,73$, dengan $t_{\text {tabel }}=$ 1,678. Karena thitung $>$ tabel,maka terdapat perbedaan hasil posttest antara kelompok 
eksperimen dan kelompok kontrol. Ada pun rekapitulasi hasil penelitian dapat dilihat pada tabel 1.

Tabel 1 RekapitulasiHasilPenelitian

\begin{tabular}{|c|c|c|c|c|}
\hline \multirow[t]{2}{*}{ Deskripsi } & \multicolumn{2}{|c|}{ Pretest } & \multicolumn{2}{|c|}{ Posttest } \\
\hline & Eksperimen & Kontrol & Eksperimen & Kontrol \\
\hline Nilai Tertinggi & 80 & 88 & 92 & 88 \\
\hline Nilai Terendah & 36 & 32 & 36 & 32 \\
\hline Rata-rata & 55,97 & 55,25 & 70,44 & 56,41 \\
\hline Standar Deviasi & 13,59 & 16,14 & 13,60 & 17,14 \\
\hline Varian & 288 & 173,275 & 151,172 & 201,739 \\
\hline \multicolumn{5}{|l|}{ Uji Normalitas } \\
\hline$x^{2}$ hitung & $-42,06$ & $-61,66$ & $-72,30$ & $-28,52$ \\
\hline$x^{2}$ tabel & 11,070 & 11,070 & 11,070 & 11,070 \\
\hline \multicolumn{5}{|l|}{ Uji Homogenitas } \\
\hline $\mathrm{F}_{\text {hitung }}$ & \multicolumn{2}{|c|}{1,41} & \multicolumn{2}{|c|}{1,5} \\
\hline $\mathrm{F}$ tabel & \multicolumn{2}{|c|}{1,80} & \multicolumn{2}{|c|}{1,80} \\
\hline \multicolumn{5}{|l|}{ Uji Hipotesis } \\
\hline $\mathrm{t}_{\text {hitung }}$ & \multicolumn{2}{|c|}{0,21} & \multicolumn{2}{|c|}{3,73} \\
\hline $\mathrm{t}$ tabel & \multicolumn{2}{|c|}{1,668} & \multicolumn{2}{|c|}{1,668} \\
\hline
\end{tabular}

\section{Pembahasan}

Berdasarkan kemampuan hasil belajar siswa berupa posttest yang telah dianalisis menggunakan deskripsi dan statistik interensial maka didapat hasil perhitungan statistik deskripsi yaitu terlihat pada rata-rata posttes kelas eksperimen sebesar 70,44 lebih besar dari kelas kontrol sebesar 56,41. Nilai rata-rata posttes kelas eksperimen lebih besar dari nilai rata-rata kelas kontrol, hal ini menunjukkan bahwa hasil belajar posttes eksperimen lebih baik dari kelas kontrol. Statistic inferensial yakni terlihat bahwa nilai thitung sebesar 3,37 lebih besar dari tabel sebesar 1,66 artinya $\mathrm{H}_{0}$ ditolak dan $\mathrm{H}_{\mathrm{a}}$ diterima,sehingga terdapat pengaruh menggunakan media permainan monopoli terhadap hasil belajar pada mata pelajaran IPS di kelas IV SDN Gugus 15 Kota Bengkulu.

Pembelajaran dengan menggunakan meida permainan monopoli memilik kelebihan yakni dapat membuat siswa lebih aktif, meningkatkan daya tarik siswa, membangkitkan keinginan dan minat baru pada siswa.Media peemainan monopoli dengan mengubah gambar pada bidak-bidak papan monopoli menjadi menjadibidak gambar yang berkaitan dengan materi pembelajaran, sehingga siswa lebih aktif dalam mengikuti pembelajaran. Hal ini diperkuat oleh Desmita (2014: 35) bahwa siswa sekolah dasar (6-12 tahun) memiliki karakteristik yaitu senang bergerak, senang bekerja dalam kelompok, dan senang merasa atau melakukan/ memperagakan sesuatu secara langsung.Dalam hal ini, siswa harus menjawab soalsoal yang ada pada bidak permainan monopoli dengan demikian siswa dapat belajar sambil bermain.

Proses pembelajaran berlangsung pada kelas eksperimen dan kelas kontrol dilaksanakan berdasarkan Rencana Pelaksanaan Pembelajaran (RPP) yang sudah dirancang sebelumnya. Proses pembelajaran yang berlangsung pada kelas eksperimen dan kelas kontrol secara keseluruhan sama. Perbedaannya terletak pada kelas eksperimen yang menggunakan media permainan monopoli pada proses pembelajaran, sedangkan pada kelas kontrol menggunakan media gambar pada proses pembelajaran. 
Pada saat pembelajaran kelas eksperimen menggunakan media permainan monopoli membagi siswa ke dalam 7 kelompok yang masing-masing beranggotakan 5 orang yang memiliki kemampuan yang berbeda, begitu juga dengan jenis kelaminnya, mereka digabungkan laki-laki dan perempuan ke dalam satu kelompok. Setiap kelompok mendapatkan papan monopoli, aturan permainan monopoli, satu buah dadu, soal, kartu jawaban, kartu materi, kartu hadiah, kartu zonk, dan uang mainan. Sesuai dengan pendapat Husna (2009: 151) mengatakan bahwa permainan monopoli adalah permainan yang menggunakan satu set peralatan monopoli yang terdiri dari papan permainan, bidak atau petak, dua buah dadu, kartu umum dan kesempatan, uang-uangan, kartu pembelian tanah.

Setiap kelompok yang telah mendapatkan satu set media permainan monopoli lalu guru mengarahkan siswa untuk membaca dan memahami peraturan media permainan monopoli. Setelah semua kelomompok telah memahami aturan permainan monopoli, setiap anggota dalam kelompok melukakan hompimpa untuk menentukan urutan permaianan dalam kelompok. Guru memberikan waktu 30 menit untuk bermain menggunakan media permainan monopoli dan menjawab setiap soal yang didapatkan dalam bidak soal. Setiap kelompok dari kelompok 1 sampai kelompok anggota kelompok semuanya ikut aktif dalam menjawab setiap soal yang siswa dapatkan dan meningkatnya daya nalar berpikir siswa, hal ini dilihat pada saat siswa menjawab soal, menyimak temannya menjawab soal, membaca setiap materi yang mereka dapatkan, dan kehebohan mereka pada saat mendapatkan kartu hadiah ataupun kartu zonk.

Setelah permainan di mulai setiap anggota dalam kelompok mendapatkan kesempatan yang sama untuk mengocok dadu secara begiliran dan berjalan searah dengan jarum jam. Anggota kelompok yang berhenti pada bidak materi akan membacakan materi sesuai dengan gambar pada bidak dan kartu materi di depan teman-teman kelompoknya. Sedangkan anggota kelompok yang mendapaat bidak soal akan mengambil satu soal dan harus menjawab pertanyaan dengan tepat sedangkan teman-teman yang lain dalam kelompok akan menyimak dengan membaca kartu jawaban yang telah disediakan, apabila siswa tidak dapat menjawab soal tersebut maka akan mendapatkan sangsi berupa membayar denda ke bank sebesar 10.000 dan jika siswa dapat menjawab pertanyaan maka siswa tersebut akan mendapat 2 point. Begitupun jika siswa berhenti pada bidak hadiah maka siswa berhak mengambil kartu hadiah dan menukarkannya pada bank. Serta jika siswa mendapatkan kartu zonk maka siswa akan mengambil kartu zonk dan membayarnya ke pada bank. Hal ini sesuai dengan pendapat Riva (2012: 91-92) tentang aturan permainan monopoli.

Pada saat pembelajaran berlangsung dengan menggunakan media permainan monopoli setiap anggota dalam kelompok berantusias untuk dapat mengumpulkan uang dan point sebanyak-banyaknya karena apabila anggota kelompok dapat menjawab banyak pertanyaan maka akan mendapatkan banyak tambahan point untuk kelompoknya. Kelompok yang mendapat point tertinggi adalah kelompok 3, 5 dengan point 80 dan point terendah didapatkan oleh kelompok 1, 5, 6 mendapat point 40, point sedang yitu 65 diperoleh oleh kelompok 2 dan kelompok 7 .

Dengan menggunakan media permainan monopoli pembelajaran menjadi menarik, menyenangkan, tidak membosankan, menimbulkan motivasi serta minat belajara siswa, sehingga mempermudah pemahaman siswa terhadap materi (Sandra, 2014: 418) tetapi juga dapat meningkatkan hasil belajar siswa pada pelajaran IPS. Hal ini dapat membuktikan kebenaran hasil penelitian Pratiwi (2017) yang menyimpulkan bahwa penggunaan media permainan monopoli dapat meningkatkan hasil belajar siswa pada pelajaran IPS. 
Pada kelas kontrol, suasana kurang kondusif dan proses pembelajaran kurang efektif bila dibandingkan dengan kelas eksperimen. Hal ini terlihat pada saat guru menjelaskan materi yang berkaitan dengan aktifitas ekonomi dalam pemanfaatan sumber daya alam di lingkungan sekitar dengan bantuan media gambar yang di tempel di depan kelas dan kemudian membentuk kelompok untuk mengerjakan tugas pada lembar diskusi siswa (lapiran 52 halaman 211). Ketika pembelajaran berlangsung banyak siswa didalam kelompok yang sibuk dengan pekerjaannya sendiri.Ini dikarenakan mereka kurang termotivasi untuk mengikuti pembelajaran karena kurang menarik.Saat guru memberikan pertanyaan kepada siswa hanya beberapa orang saja yang menunjukkan tangan untuk menjawab pertanyaan yang diajukan oleh guru dan siswa juga cukup kesulitan dalam mengerjakan posttes yang diberikan (foto 52 halaman 212).Dari temuan-temuan tersebut sudah terlihat adanya perbedaan kegiatan pembelajaran yang berlangsung antara kelas kontrol dengan kelas eksperimen.

Pemberian posttes pada kedua kelas dengan soal yang sama setelah pembelajaran berlangsung menunjukkan bahwa hasil posstest yang diperoleh oleh siswa pada kelas eksperimen dan kelas kontrol terlihat berbeda. Hal inni menunjukkan bahwa secara keseluruhan penggunaan media permainan monopoli memberikan pengaruh yang signifikan terhadap hasil belajar siswa.

\section{Simpulan}

Berdasarkan data hasil penelitian di SDN Gugus I5 Kota Bengkulu, pengolahan data, analisis serta pembahasan maka dapat disimpulkan bahwa terdapat pengaruh penggunaan meida permainan monopoli terhadap hasil belajar siswa pada pembelajaran IPS di Kelas IV SDN Gugus I5 Kota Bengkulu. Hal ini ditunjukkan dengan perhitungan uji-t pada pretest yaitu $\mathrm{t}$ hitung $(0,21)<\mathrm{t}$ tabel $(1,668)$ yang artinya tidak terdapat perbedaan rata-rata pada kelas ekperimen dan kelas kontrol, pada posttest thitung $(3,73)>t_{\text {tabel }}(1,668)$ yang artinya terdapat perbedaan rata-rata pada kelas ekperimen dan kelas kontrol. Kenaikan pretest-posttest pada kelas eksperimen sebesar 25,85\%, sedangkan pada kelas kontrol kenaikan pretest-posttes sebesar $2,09 \%$. Dari kenaikan pretest-posttest menunjukkan bahwa kenaikan kelas ekperimen lebih tinggi, hal ini menunjukkan bahwa terdapat pengaruh penggunaan media permainan monopoli terhadap hasil belajar siswa pada pembelajaran IPS di Kelas IV SDN Gugus I5 Kota Bengkulu.

Perbedaan ditunjukkan kelompok eksperimen setelah mengikuti pembelajaran menggunakan media permainan monopoli pembelajaran menjadi menarik, menyenangkan, tidak membosankan, menimbulkan motivasi serta minat belajara siswa, sehingga mempermudah pemahaman siswa terhadap materi sehingga membuat pembelajaran lebih bermakna.

\section{Saran}

Berdasarkan hasil penelitian yang dilakukan, maka peneliti mengemukakan beberapa saran sebagai berikut.

1. Bagi guru yang ingin menggunakan media permainan monopoli sebaiknya menetapkan aturan yang harus ditaati terlebih dahulu sebelum permainan dimulai agar dapat membuat kelas kondusif.

2. Bagi peneliti selanjutnya diharapkam dapat mengembangkan media permainan monopoli dengan model yang lebih menarik dan kreatif lagi. 


\section{Referensi}

Aziza, N. 2013. Penerapan Media Monopoli Untuk Meningkatkan Hasil Belajar Siswa PadaMata Pelajaran Ipa Di Sekolah Dasar. PGSD FIP.Universitas Negeri Surabaya. Volume 01 Nomor 02.

Desmita. 2012. Psikologi Perkembangan Peserta Didik. Bandung: Remaja Rosdakarya.

Husna, A. 2009. 100+Permainan Tradisional Indonesia untuk kreativitas, ketangkasan, dan keakraban. Yogyakarta.ANDI.

Pratiwi, R. 2017. Penggunaan Media Permainan Monopoli Mata Pelajaran IPS Untuk Meningkatkan Hasil Belajar Siswa Kelas IV SDN Kendalkemlangi Lamongan.PGSD. Fakultas Ilmu Pendidikan. Universitas Negeri Surabaya.Volume 5 nomor 03.

Riva, I. 2012. Koleksi Game Edukatif di Dalam dan Luar Sekolah. Jogjakarta. Flash Book.

Sandra, L. 2014. Pengembangan Media Pembelajaran Permainan Monopoli Pada Pokok Materi Perkembangan Kerajaan Hindu-Buddha Di Indonesia Kelas Xi-Ipa 2 Sma Negeri 1 Driyorejo. Fakultas Ilmu Sosial.Universitas Negeri Surabaya.e-Journal Pendidikan Sejara. Vol 2.

Sugiyono. 2017. Metode Penelitian Pendidikan Pendekatan Kuantitatif, Kualitatif, dan R\&D.Bandung: Alfabeta. 